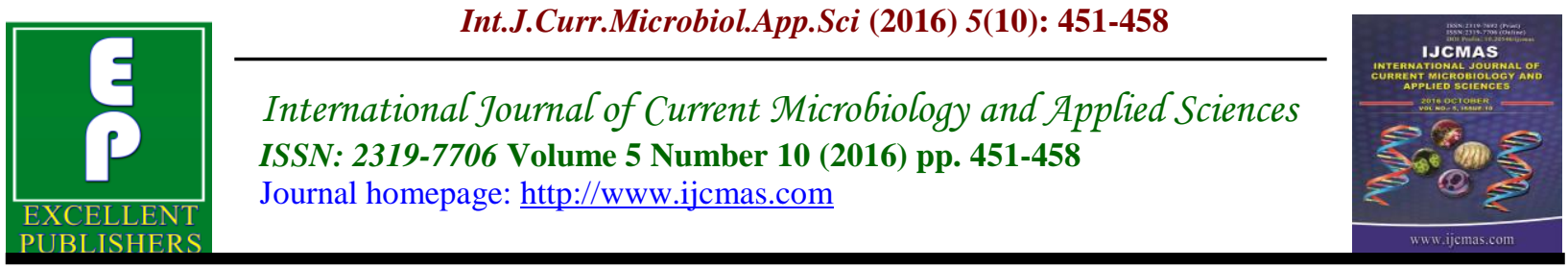

Original Research Article

http://dx.doi.org/10.20546/ijcmas.2016.510.051

\title{
Gene Sequence Polymorphisms Mutations in PFMDR-1 and PFCRT-O Genes of Plasmodium falciparum
}

\author{
Gurjeet Singh $^{1 *}$, Raksha Singh ${ }^{1}$, A.D. Urhekar ${ }^{2}$ and Kshitija Rane ${ }^{3}$ \\ ${ }^{1}$ Department of Microbiology, NC Medical College and Hospital, Israna, \\ Panipat-132107, Haryana, India \\ ${ }^{2}$ Department of Microbiology, MGM Medical College and Hospital, Kamothe, \\ Navi Mumbai-410209, Maharashtra, India \\ ${ }^{3}$ Central Research Laboratory, MGM Medical College and Hospital, Kamothe, \\ Navi Mumbai-410209, Maharashtra, India \\ *Corresponding author
}

A B S T R A C T

Keywords

Malaria drug resistance testing, Plasmodium falciparum, polymerase chain reaction, Navi Mumbai, Gene sequencing, microtitre plate.

\section{Article Info}

Accepted:

17 September 2016

Available Online:

10 October 2016
Malaria still causes severe infection in human being and responsible for high mortality in the world. Different approaches have been developed to monitor the extent of antimalarial drug resistance and to determine the biologic mechanisms by which the parasite has evaded the action of the drug. The aim of this study was to find the mutations (N86Y and $\mathrm{K} 76 \mathrm{~T}$ ) in chloroquine drug resistance genes in Plasmodium falciparum from human blood. Total 22 positive samples of Plasmodium falciparum were included in this study. Chloroquine drug sensitivity testing was performed using method as per WHO III plate (micro test). Nested PCR was done for detection of pfcrt-o (Plasmodium falciparum chloroquine resistance transporter-o) and pfmdr-1 (Plasmodium falciparum multidrug resistance-1) genes of $P$. falciparum. Gene sequencing was done using Sanger method to find the mutations (N86Y) Pfmdr-1 and Pfcrt-o (K76T) associated with chloroquine drug resistance. Out of 22 P. falciparum 15 (68.18\%) samples were Chloroquine resistance by method similar to (micro test) WHO III plate method and nested PCR which were also showed N86Y mutation in Pfmdr-1 (Plasmodium falciparum multidrug resistant-1) gene, and same number K76T mutation was seen in pfcrt-o gene of Plasmodium falciparum. Gene sequencing is highly sensitive and specific molecular method and it could be able to differentiate between wild type and mutant type gene hence we recommend this method for point mutation which is most useful for detection of exact point where mutation occurred.

\section{Introduction}

Malaria is a life-threatening disease caused by parasites that are transmitted to people through the bites of infected female mosquitoes. According to WHO about 3.2 billion people (almost half of the world's population) are at risk of malaria, approximate 300-500 million malaria cases occurred every year, $90 \%$ of the total cases occurred in Africa and Asia. 700,000 to 2.7 million cases mortality occurred worldwide (Kumar et al., 2007). According to UNICEF a child dies at every minute from malaria in 


\section{Africa}

(http://www.unicef.org/prescriber/eng_p18.p df). 1.2 billion cases are at risk of malaria, most of whom live in India. However, Southeast Asia contributed 2.5 million cases to the global burden of malaria. Of this, India alone contributed $76 \%$ of the total cases (Kumar et al., 2007). 1.5 million cases of malaria are reported annually in India, out of which $50 \%$ cases are due to Plasmodium falciparum alone. Chloroquine has been the most effective drug in the treatment of noncomplicated malaria.

A sudden rise in $P$. falciparum cases has been caused by resistance towards chloroquine, which was used for a long time as the first line of treatment of malaria cases (Kumar, 2013). Drug resistance may lead to high morbidity and mortality in $P$. falciparum cases. Drug chloroquine acts by interfering with heme metabolism in the digestive vacuole of the parasite $P$. falciparum and resulting chloroquine resistance due to reduced accumulation of the drug by the parasites (Fitch, 1970; Douki et al., 2011; Sanchez et al., 2010). Various genetic alterations have been shown to be associated with chloroquine resistance. Mainly, two genes known as $P$. falciparum multidrug resistance gene Pfmdr1, which codes for Pgh1, a Pglycoprotein homologue, and the chloroquine resistance transporter gene Pfcrt, which codes for chloroquine resistance transporter protein have been identified as potential candidates of chloroquine resistance.

There are several point mutations occurred in Pfmdr1 gene at positions 754, 1049, 3598, 3622 and 4234 result in amino acid changes at codons 86, 184, 1034, 1042 and 1246, respectively. These amino acid changes have been shown to be associated with chloroquine resistance (Foote et al., 1990; Cox-Singh et al., 1994; Duraisingh et al., 1997; Chaijaroenkul et al., 2011; Atroosh et al., 2012). Out of the several mutations described, the mutation in codon 86 (from asparagine to tyrosine, N86Y), involved in the substrate specificity of the gene product (P- glycoprotein), appears to be the most important as this may alter the transport activity of the protein.

\section{Materials and Methods}

This prospective and analytical study was conducted at Department of Microbiology and Central Research Laboratory, MGM Medical College and Hospital, Navi Mumbai, India and Eurofins Genomics India over a period of one year from January 2014 to December 2014. Total of 22 Plasmodium falciparum positive blood samples were included in the study. The control ATCC Plasmodium falciparum (3D7) chloroquine sensitive strain was procured from Haffkine Institute for Training, Research \& Testing, Mumbai and Indian Institute of Technology Bombay, Powai, Mumbai, India. Parasitic index was determined before antimalarial drug sensitivity test.

\section{Ethical clearance}

The study protocol was reviewed and approved by the Ethical Review Committee of MGM Institute of Health Sciences (Deemed University), Navi Mumbai. Informed written consent was obtained from the patients before start the study.

Inclusion criteria: All patients with clinical suspicion of malaria.

Exclusion criteria: Patients on antimalarial treatment were excluded from study.

For drug sensitivity and molecular analysis, approximately $5 \mathrm{ml}$ of venous blood was collected from the malaria suspected patients $(2 \mathrm{ml}$ for thick and thin smear and 3 
ml for DNA extraction) who were tested positive for Plasmodium falciparum using thick and thin blood smear and stained with Leishman's stain.

\section{In vitro sensitivity testing}

Antimalarial drug sensitivity testing was performed in vitro micro test (Mark III) according to Singh et al. The chloroquine drug sensitivity test was performed immediately after the collection of blood. The test was considered valid and interpretable if $10 \%$ of the parasites in the control well (drug free well) had developed into the schizonts after 24-36 hours incubation. Isolates were considered resistant if they showed schizont maturation at chloroquine concentrations $8 \mathrm{pmol} /$ well (1.6 $\mathrm{mmol} / \mathrm{L}$ blood). To evaluate the drugparasite response, the EC50 value (50\% inhibition) was calculated by HN Non Lin (V. 1.01 Beta) Software.

The $3 \mathrm{ml}$ blood was stored in cryo vials and stored in at $-20^{\circ} \mathrm{C}$ for DNA extraction and molecular study.

\section{DNA extraction}

The DNA extractions of above samples were performed by using DNA Mini Kit (Invitrogen) spin column method.

\section{Primer Design}

Primers used in this study were design from published articles. Primers were procured from Eurofins Genomics India. Primers for nested PCR for detection of drug resistant gene in malaria parasites were selected from published articles (Purfield et al., 2004; Sidhu et al., 2002; Singh et al., 2015.) P. falciparum -Pfmdr1 forward primer - 5'TGTATGTGCTGTATTATCAGGAGGA AC-3', reverse primer-5'-AATTGTACTA AACCTATAGATACTAATGATAATATT
ATAGG-3' (gene acession No.JN578609.1), pfcrt-o forward primer - 5'TGAGAATTAGAT AATTTAGTACAA GAAGGAA-3' (gene ascension No. JF520758.1), reverse primer-CGTGAGC CATCTGTTAAGGTC (gene ascension No.AF030694.2)

\section{Polymerase Chain Reaction}

DNA was extracted from $200 \mu 1$ of EDTA blood with the DNA extraction kit (Invitrogen, USA) according to the manufacturer's instructions and stored at $4^{\circ} \mathrm{C}$ until PCR could be completed. Nested PCR amplifications were performed in accordance to a standard procedure within the cycling parameters by using a PeqSTAR 96Xx Universal Gradient PCR thermal cycler (Peqlab, Germany). Known positive and negative samples from previous malaria diagnosed or uninfected individuals were used as controls. DNA bands were documented by gel documentation system (BioEra, India).

\section{Purification of amplified product}

5 volumes Buffer PB was added to 1 volume of the PCR reaction and mix. If the color of the mixture is orange or violet, add $10 \mu \mathrm{l} 3$ $\mathrm{M}$ sodium acetate, $\mathrm{pH} 5.0$, and mix. The color of the mixture will turn yellow. Place a QIAquick column in $\mathrm{S}$ a provided $2 \mathrm{ml}$ collection tube or into a vacuum manifold. To bind DNA, apply the sample to the QIAquick column and S centrifuge for 30$60 \mathrm{~s}$ or apply vacuum to the manifold until all the samples have passed through the column. Discard flow-through and place the QIAquick column back in the same tube. To wash, add $0.75 \mathrm{ml}$ Buffer $\mathrm{PE}$ to the QIAquick column S centrifuge for 30-60 s or apply vacuum. S Discard flow-through and place the QIAquick column back in the same tube. Centrifuge the QIAquick column once more in the provided $2 \mathrm{ml}$ collection 
tube for $1 \mathrm{~min}$ to remove residual wash buffer. Place each QIAquick column in a clean $1.5 \mathrm{ml}$ microcentrifuge tube. To elute DNA, add $50 \mu \mathrm{l}$ Buffer EB (10 mM Tris Cl, $\mathrm{pH} 8.5)$ or water $(\mathrm{pH} \mathrm{7.0-8.5)}$ to the center of the QIAquick membrane and centrifuge the column for $1 \mathrm{~min}$. For increased DNA concentration, add $30 \mu$ l elution buffer to the center of the QIAquick membrane, let the column stand for $1 \mathrm{~min}$, and then centrifuge. If the purified DNA is to be analyzed on a gel, add 1 volume of Loading Dye to 5 volumes of purified DNA. Mix the solution by pipetting up and down before loading the gel.

\section{Gene Sequencing}

Gene sequencing of drug resistance genes (Pfmdr-1 and Pfcrt-o) of malarial parasites was done using Sanger method, [ChemistryBig dye terminator, Gel - Pop 7 polymer, Machine- 3730XL DNA Analyzer (Applied Biosystems $^{\circledR}$ )).

\section{Results and Discussion}

The present study was conducted to find out the drug resistance in patients attending a Tertiary care Hospital, Navi Mumbai. Out of 22 samples of Plasmodium falciparum 15 samples (68.18\%) showed drug resistance by in vitro drug sensitivity phenotypic method and by PCR method. The nested PCR products of pvcrt-o and pvmdr-1 from the above samples were directly sequenced in both directions i.e. forward and reverse. Gene sequencing of 15 samples were showed N86Y mutation in all 15 samples and no samples were showed wild type in Pfmdr-1 (Plasmodium falciparum multidrug resistant-1) gene, and same number K76T mutation was seen in pfcrt-o gene of Plasmodium falciparum. Whereas Plasmodium falciparum 3D7 which is a known chloroquine sensitive strain was used as control and neither mutant type nor wild type (Pfmdr-1 and Pfcrt-o) seen. Patients samples were showed mutation wild type and mutant type which is associated with chloroquine drug resistance (Table 1) (Figure $1 \& 2$ ).

The Plasmodium falciparum isolates in this study derive from Navi Mumbai, India where malaria is endemic; the confirmation of $P$. falciparum was confirmed by both clinical and laboratory testing.

The emergence of drug-resistance poses a major obstacle to the control of malaria. A homolog of the major multidrug-transporter in mammalian cells was identified i.e. pfmdr1. Several studies have demonstrated strong, although incomplete, associations between resistance to the widely used antimalarial drug chloroquine and mutation of the pfmdr1 gene in both laboratory and field isolates. Genetic studies have confirmed a link between mutation of the pfmdr1 gene and chloroquine-resistance.

Table.1 Drug sensitivity pattern of Plasmodium falciparum.

\begin{tabular}{|l|l|c|c|c|c|}
\hline Sample & In vitro drug & \multicolumn{2}{|c|}{ Codon-86 pfmdr-1 } & \multicolumn{2}{|c|}{ Codon-76 pfcrt-o } \\
\cline { 3 - 6 } & sensitivity status & Allele N86 & Allele 86Y & Allele K76 & Allele 76T \\
\hline $\begin{array}{l}\text { 3D7 strain } \\
(n=1)\end{array}$ & CQS* $(n=1)$ & 1 & 0 & 1 & 0 \\
\hline $\begin{array}{l}\text { Patient samples } \\
(n=22)\end{array}$ & $\begin{array}{l}\text { CQR* }(n=15) \\
\text { CQS* }(n=07)\end{array}$ & 07 & 15 & 07 & 15 \\
\hline
\end{tabular}

$\mathrm{CQR}^{*}=$ Chloroquine resistance

$\mathrm{CQS}^{*}=$ Chloroquine sensitive 
Fig.1 Mutant allele 86Y mutation in pfmdr-1 gene

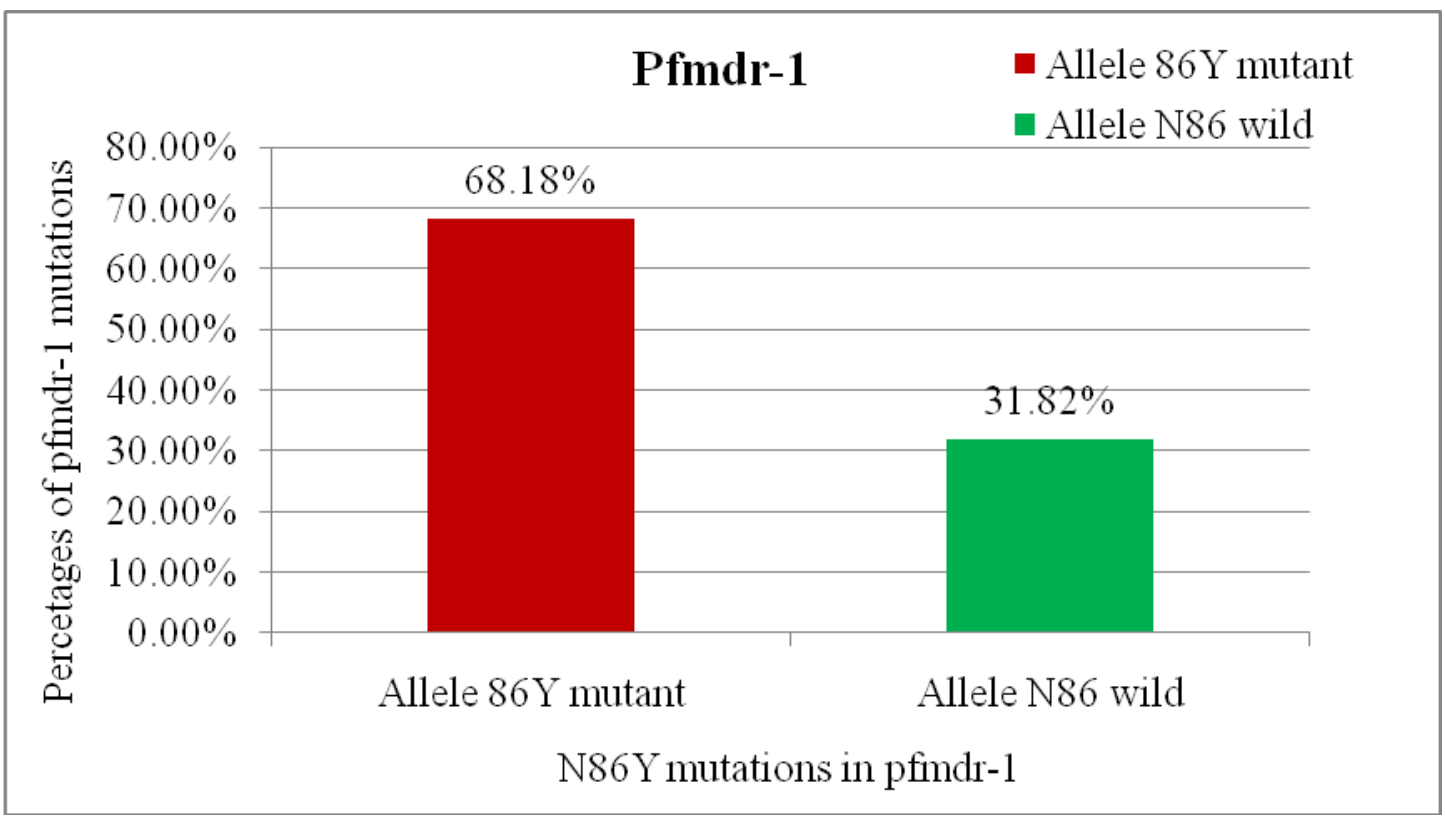

Fig.2 Mutant allele 76Y mutation in pfcrt-o gene

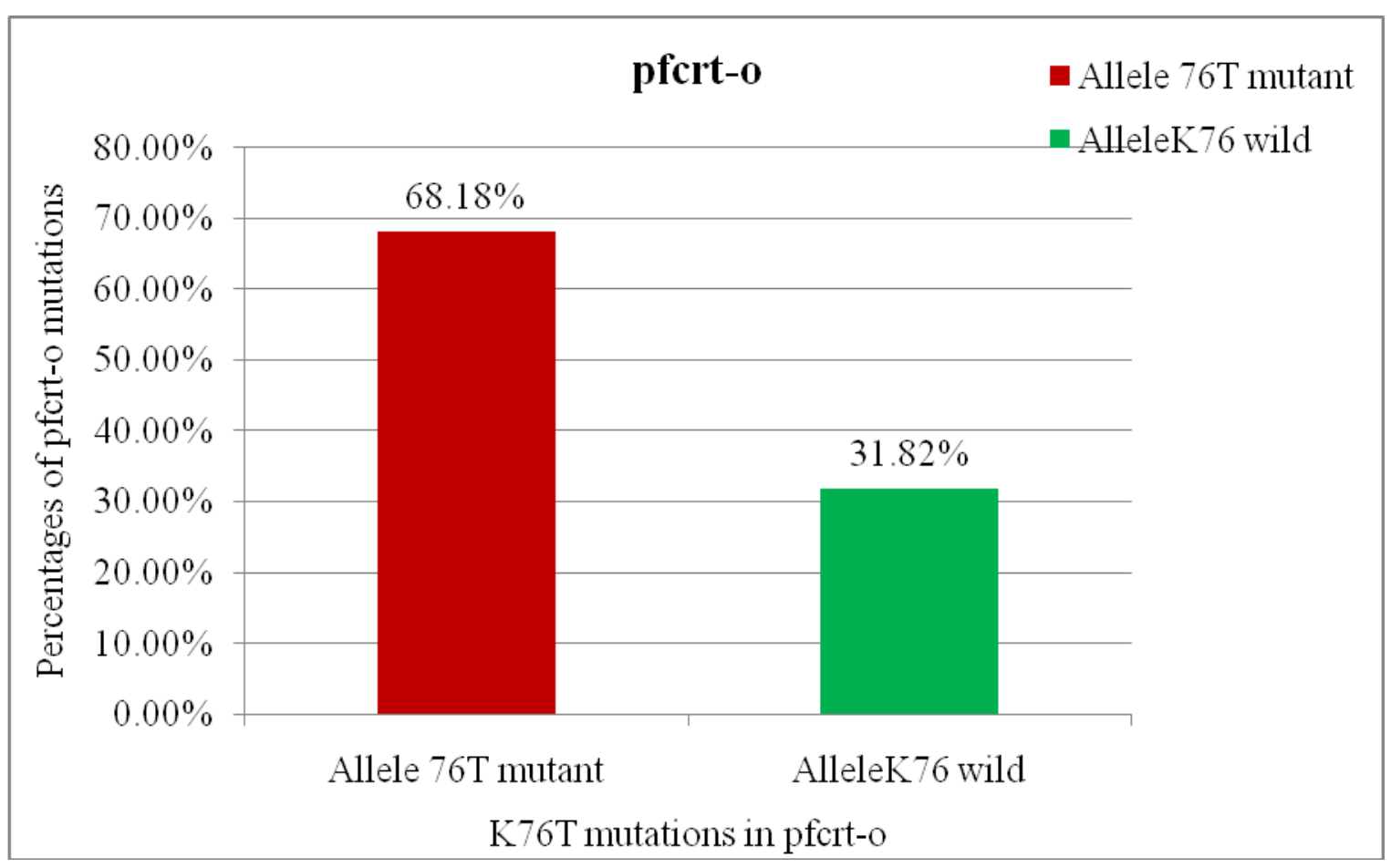


Fig.3 Mutant $86 Y$ in Pfmdr-1 gene

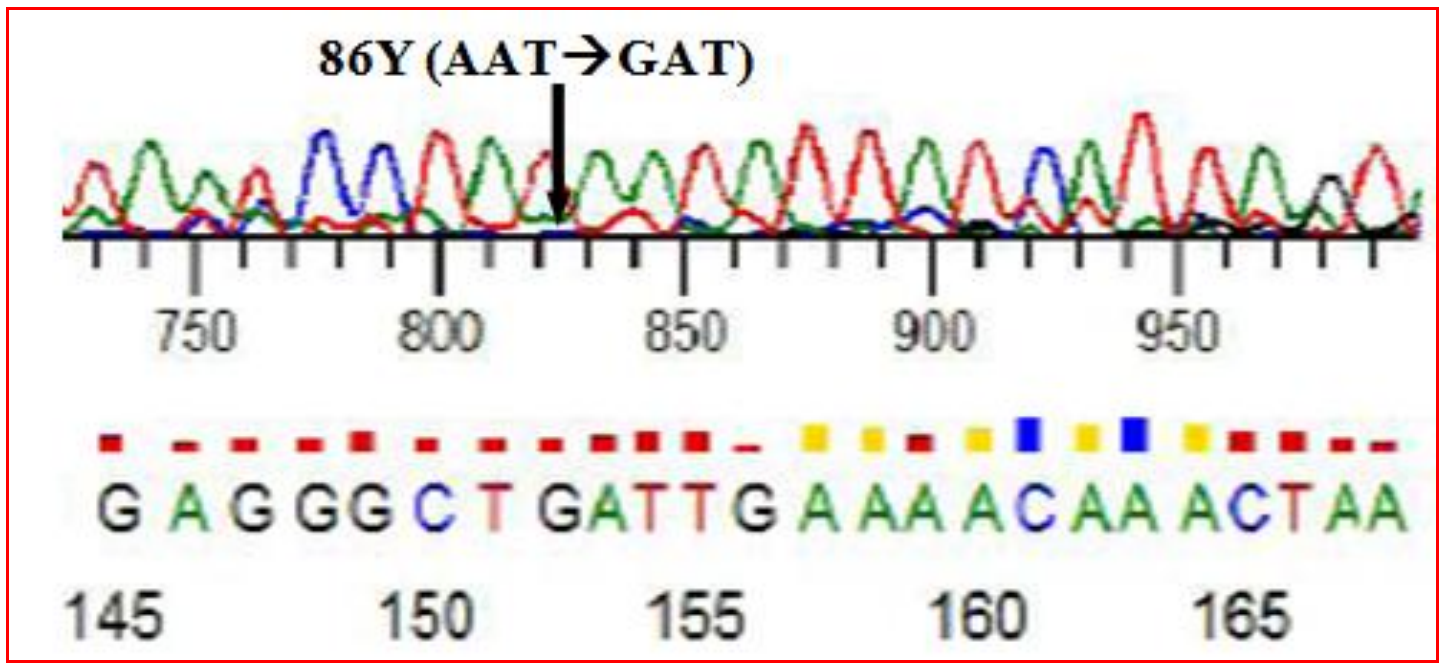

Fig.4 Mutant 76T in Pfcrt-o gene

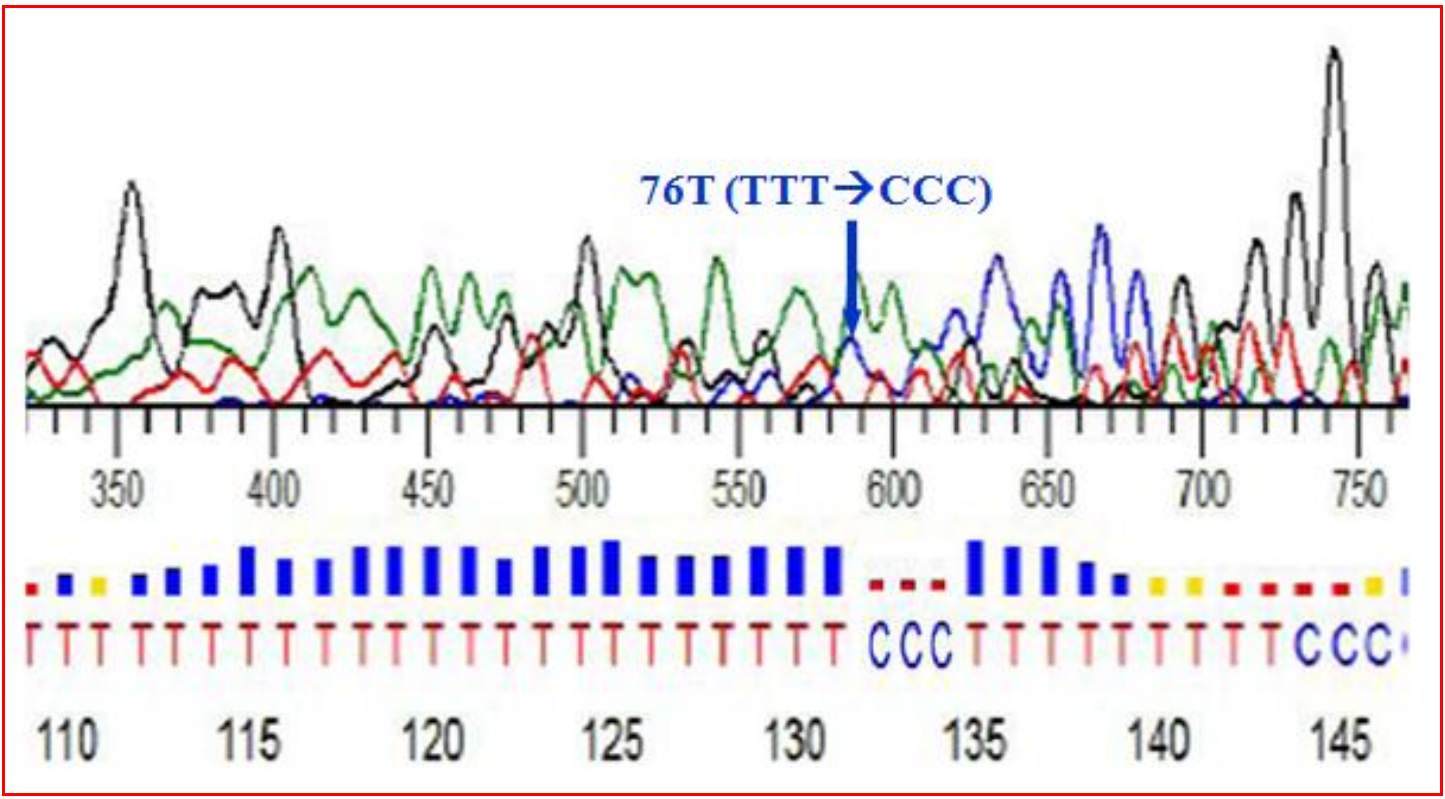

Although not essential for chloroquineresistance, pfmdr1 plays a role in modulating levels of resistance. At the same time it appears to be a significant component in resistance to the structurally related drug quinine. A strong association has been observed between possession of the pfmdr-1 and pfcrt-o.

Chloroquine drug is the drug which also taken during prophylaxis from malaria.
Polymorphism in pfmdr1 and gene amplification has been observed throughout the world and their usefulness in predicting resistance levels is influenced by the history of drug selection of each population

In our study $68.18 \%$ detection of $86 \mathrm{Y}$ mutant in codon 86 of pfmdr- 1 is closer to findings of other workers (Shrivastava et al., 2014; Sutar et al., 2011; Jalousian et al., 
2008). In our study $68.18 \%$ samples showed presence 76T mutant in codon 76 of pfcrt-o. This finding is closer to work reported by other workers (Shrivastava et al., 2014; Sutar et al., 2011; Jalousian et al., 2008).

In conclusion, the molecular methods are highly useful to monitor chloroquine drug resistance, assessing in vitro chloroquine. 86 Y mutant in codon 86 of pfmdr-1 Pfmdr-1 along with $76 \mathrm{~T}$ mutant in codon 76 of pfcrto can be useful detect chloroquine drug resistance in Plasmodium falciparum.

\section{Acknowledgement}

Authors thankful to thank Dr. Saroj Bapna Scientific Officer, Haffkine Institute for Training, Research and Testing, Parel, Mumbai and Prof. Swati Patankar, Department of Biosciences and Bioengineering, IIT Bombay, Powai, Mumbai for providing 3D7 ATCC strain of Plasmodium falciparum.

\section{References}

Adagu, I.S., Dias, F., Pinheiro, L., Rombo, L., do Rosario, V., Warhurst, D.C. 1996. Guinea Bissau: association of chloroquine resistance of Plasmodium falciparum with the Tyr86 allele of the multiple drug-resistance gene Pfmdr1. Trans. R. Soc. Trop. Med. Hyg., 90(1): 90-91.

Anvikar, A.R., Sharma, B., Sharma, S.K., Ghosh, S.K., Bhatt, R.M., Kumar, A., Mohanty, S.S., Pillai, C.R., Dash, A.P., Valecha, N. 2012. In vitro assessment of drug resistance in Plasmodium falciparum in five States of India. Indian J. Med. Res., 135: 494-499.

Atroosh, W.M., Mekhlafi, H.M., Mahdy, M.A.K., Surin, J. 2012. The detection of pfcrt and pfmdr1point mutations as molecular markers of chloroquine drug resistance, Pahang, Malaysia. Malaria J., 11: 251.

Babiker, H.A., Pringle, S.J., Abdel-Muhsin, Mackinnon, A.M., Hunt, P., and Walliker, D. 2001. High-Level Chloroquine Resistance in Sudanese Isolates of Plasmodium falciparum Is Associated with Mutations in the Chloroquine Resistance Transporter Gene pfcrt and the Multidrug Resistance Gene pfmdr1. J. Infect. Dis., 183: 15358.

Basco, L.K., Le Bras, J., Rhoades, Z., Wilson, C.M. 1995. Analysis of pfmdr1 and drug susceptibility in fresh isolates of Plasmodium falciparum from subSaharan Africa. Mol. Biochem. Parasitol., 74(2): 157-66.

Chaijaroenkul, W., Ward, S.A., Mungthin, M. 2011. Sequence and gene expression of chloroquine resistance transporter (pfcrt) in the association of in vitro drugs resistance of Plasmodium falciparum. Malaria J., 10: 42.

Cox-Singh, J., Singh, B., Alias, A., Abdullah, M.S. 1995. Assessment of the association between three pfmdr1 point mutations and chloroquine resistance in vitro of Malaysian Plasmodium falciparum isolates. Trans. $R$. Soc. Trop. Med. Hyg., 89(4): 436-7.

Douki, J.B.L., Boutamba, S.D.D., Zatra, R., Edou, S.E.Z., Ekomy, H., et al. 2011. Increased prevalence of the Plasmodium falciparum Pfmdr1 86N genotype among field isolates from France ville, Gabon after replacement of chloroquine by artemether-lumefantrine and artesunate-mefloquine. Infect. Gen. Evo., 11: 512-517.

Duraisingh, M.T., Drakeley, C.J., Muller, O., Bailey, R., Snounou, G., et al. 1997. Evidence for selection for the tyrosine86 allele of the pfmdr 1 gene of Plasmodium falciparum by chloroquine and amodiaquine. Parasitol., 114: 20511.

Fitch, C.D. 1970. Plasmodium falciparum in owl monkeys: drug resistance and 
chloroquine binding capacity. Sci., 169(942): 289-90.

Foote, S.J., Kyle, D.E., Martin, R.K., Oduola, A.M., Forsyth, K., et al. 1990. Several alleles of the multidrug-resistance gene are closely linked to chloroquine resistance in Plasmodium falciparum. Nature, 345(6272): 255-58.

Jalousian, F., Dalimi, A., Samiee, S.M., Ghaffarifar, F., Soleymanloo, F., Naghizadeh, R. 2008. Mutation in pfmdr1 gene in chloroquine-resistant Plasmodium falciparum isolates, Southeast Iran. Int. J. Infect. Dis., 12: 630-634.

Kumar, A., Valecha, N., Jain, T., Dash, A.P. 2007. Burden of Malaria in India: Retrospective and Prospective View. Am. J. Trop. Med. Hyg., 77(6): 6978.http://www.unicef.org/prescriber/eng _p18.pdf

Lim, P., Chy, S., Ariey, F., Incardona, S., Chim, P., Sem, R., Denis, M.B., Hewitt, S., Hoyer, S., Socheat, D., MerecreauPuijalon, O., Fandeur, T. 2003. pfcrt Polymorphism and Chloroquine Resistance in Plasmodium falciparum Strains Isolated in Cambodia. Antimicrob. Agents Chemother., 47(1): 87-94.

Murambiwa, P., Masola, B., Govender, T. 2011. Anti-malarial drug formulations and novel delivery systems: A review. Acta Tropical, 18: 71-79.

National Drug Policy on Malaria. 2013. Directorate General of National Vector Borne Disease Control Programme, Ministry of Health \& Family Welfare, Government of India. New Delhi: 1-15.

Purfield, A., Nelson, A., Laoboonchai, A., Congpuong, K., McDaniel, P., Miller,
R.S., Welch, K., Wongsrichanalai, C., Meshnick, S.R. 2004. New method for detection of pfmdr1 mutations in Plasmodium falciparum DNA using real-time PCR. Malaria J., 3(9).

Sanchez, C.P., Dave, A., Stein, W.D., Lanzer, M. 2010. Transporters as mediators of drug resistance in Plasmodium falciparum. Int. J. Parasitol., 40: 11091118.

Shrivastava, S.K., Gupta, R.K., Mahanta, J., Dubey, M.L. 2014. Correlation of Molecular Markers, Pfmdr1-N86Y and Pfcrt-K76T, with In Vitro Chloroquine Resistant Plasmodium falciparum, Isolated in the Malaria Endemic States of Assam and Arunachal Pradesh, Northeast India. PLoS ONE, 9(8): e103848.

doi:10.1371/journal.pone.0103848.

Sidhu, A.B., Verdier-Pinard, D., Fidock, D.A. 2002. Chloroquine resistance in Plasmodium falciparum malaria parasites conferred by pfcrt mutations. Sci., 298(5591): 210-3.

Singh, G., Urhekar, A.D., Raksha. 2015. In Vitro Antimalarial Drug Sensitivity Testing For Plasmodium falciparum and Plasmodium vivax. IOSR J. Dent. Med. Sci., 14(4): 4955.http://www.meduniwien.ac.at/user/ha rald.noedl/malaria/download.html.

Sutar, S.K.D., Gupta, B., Ranjit, M., Kar, S.K., Das, A. 2011. Sequence analysis of coding DNA fragments of pfcrt and pfimdr-1 genes in Plasmodium falciparum isolates from Odisha, India. Mem Inst Oswaldo Cruz, Rio de Janeiro, 106(1): 78-84.

\section{How to cite this article:}

Gurjeet Singh, Raksha Singh, A.D. Urhekar and Kshitija Rane. 2016. Gene Sequence Polymorphisms Mutations in PFMDR-1 and PFCRT-O Genes of Plasmodium falciparum. Int.J.Curr.Microbiol.App.Sci. 5(10): 451-458. doi: http://dx.doi.org/10.20546/ijcmas.2016.510.051 